Agnès Renault, D'une île rebelle à une île fidèle, les Français de Santiago de Cuba (1791-1825)

Mont-Saint-Aignan, Publications des Universités de Rouen et du Havre, 2012

Jean-Claude Halpern

\title{
OpenEdition
}

Journals

Édition électronique

URL : https://journals.openedition.org/ahrf/13304

DOI : $10.4000 /$ ahrf. 13304

ISSN : 1952-403X

Éditeur :

Armand Colin, Société des études robespierristes

Édition imprimée

Date de publication : 15 octobre 2014

Pagination : 200-202

ISBN : 978-2-20-092927-5

ISSN : 0003-4436

Référence électronique

Jean-Claude Halpern, " Agnès Renault, D'une île rebelle à une île fidèle, les Français de Santiago de Cuba (1791-1825) », Annales historiques de la Révolution française [En ligne], 377 | juillet-septembre 2014, mis en ligne le 15 septembre 2014, consulté le 01 juillet 2021. URL : http://journals.openedition.org/ahrf/ 13304 ; DOI : https://doi.org/10.4000/ahrf.13304

Ce document a été généré automatiquement le 1 juillet 2021.

Tous droits réservés 


\section{Agnès Renault, D'une île rebelle à une île fidèle, les Français de Santiago de Cuba (1791-1825)}

Mont-Saint-Aignan, Publications des Universités de Rouen et du Havre, 2012

Jean-Claude Halpern

\section{RÉFÉRENCE}

Agnès Renault, D’une île rebelle à une île fidèle, les Français de Santiago de Cuba (1791-1825),

Mont-Saint-Aignan, Publications des Universités de Rouen et du Havre, 2012, 528 p.,

ISBN 978-2-87775-531-3, $31 €$

1 Ce livre est le résultat d'un travail de recherches qui conduit Agnès Renault sur les traces des Français qui, entre 1791 et 1825, ont été à l'origine de l'essor de l'Orient cubain, autour de Santiago de Cuba et face aux côtes haïtiennes. Des Cubains s'étaient déjà intéressé au $\mathrm{XIX}^{\mathrm{e}}$ siècle à l'origine de cette influence française qui a laissé sa marque jusqu'à nos jours dans cette partie de l'île, mais c'est la thèse d'Alain Yacou en 1975, sur L'Émigration à Cuba des colons français de Saint-Domingue qui a relancé l'intérêt sur cette question.

2 Planteurs fuyant les troubles qui agitent la colonie française jusqu'à l'indépendance en 1804, réfugiés plus ou moins démunis, parfois arrivés avec leurs esclaves, blancs ou hommes de couleur, venus majoritairement des régions longtemps occupées par les Anglais, des parties Ouest ou Sud de Saint-Domingue, ils ont gardé dans l'adversité le même esprit d'entreprise qui les amène sans se décourager à entreprendre par la culture du café, sur le modèle de la plantation esclavagiste qui a fait une première fois leur fortune, la mise en valeur des pentes délaissées qui entourent la deuxième ville de cette colonie espagnole somnolente qu'est l'île de Cuba. Installation au début considérée comme temporaire selon les vicissitudes des événements de Saint- 
Domingue, marquée par des va-et-vient d'une île à l'autre, voire avec La NouvelleOrléans ou les États-Unis, elle est considérée parfois avec une certaine suspicion par les autorités espagnoles, très ambivalentes à l'égard des Français, plus encore accompagnés d'esclaves imprégnés d'un esprit de révolte potentiellement dangereux.

3 Les réfugiés suscitent cependant l'admiration ou l'envie par leur dynamisme économique; ils sont considérés avec une certaine bienveillance par le gouverneur de Santiago, d'autant plus que leur activité corsaire devient essentielle au ravitaillement d'une ville en plein essor démographique, mais ils sont en butte à l'hostilité de l'archevêque, hostile au modèle économique de la plantation, ou aux commerçants catalans qui redoutent leur concurrence.

4 L'invasion de l'Espagne par Napoléon entraîne l'expulsion de plusieurs milliers de Français, à l'exception de quelques centaines d'entre eux, naturalisés ou pratiquant des professions indispensables. Mais beaucoup reviennent, en particulier à partir de 1812 ou plus encore de 1814 , et s'installent d'une manière définitive. Plus encore une nouvelle vague migratoire amène cette fois des migrants volontaires, pour beaucoup venus de l'Ouest de la France rejoindre des membres de leur famille, héritiers du mythe américain de leurs prédécesseurs domingois du siècle précédent, mais cette fois dans une colonie sous souveraineté espagnole, dont la stabilité les rassure, à l'abri des mouvements de contestation qui agitent la Terre Ferme.

Car l'essor de l'économie de plantation à Cuba au XIX siècle, à la source d'un enrichissement considérable, a pour corollaire la multiplication du nombre des esclaves et la diminution relative de la population blanche, traumatisée par la révolution haïtienne toute proche. Aussi l'île se tient-elle à l'écart des mouvements indépendantistes du continent latino-américain.

6 Les Français, au début du XIX siècle, avaient réussi à reconstituer une société sur le modèle de Saint-Domingue, privilégiant les relations entre eux, parvenant ainsi à s'adapter aussi bien à Cuba, à la Jamaïque qu'à La Nouvelle-Orléans. Dans l'île espagnole, ils consolident le vieux système colonial, et pourtant, ce sont eux qui ont introduit la franc-maçonnerie, contribuant à diffuser des idées libérales à l'origine d'un mouvement émancipateur.

7 Par-delà 1825, année de l'abandon définitif des rêves d'un retour à Saint-Domingue, l'immigration française a perduré jusque dans les années soixante du xIX siècle. Les immigrants se sont peu à peu intégré et leur présence a laissé des traces sensibles dans l'Orient cubain, dans la langue, la musique ou la danse, ou le raffinement d'une certaine manière de vivre.

8 L'étude très fouillée d'Agnès Renault, qui s'appuie sur le dépouillement de nombreuses archives cubaines et s'accompagne d'une brève annexe statistique et d'un cahier iconographique et de plusieurs reproductions de cartes ou de plans d'époque, a le mérite de souligner, par-delà l'indépendance d'Haïti, la perpétuation pendant une partie du $\mathrm{XIX}^{\mathrm{e}}$ siècle du modèle colonial esclavagiste qui avait fait la fortune de la SaintDomingue française, sous la souveraineté d'une Espagne pourtant radicalement contestée sur l'ensemble du continent américain. 